\title{
Urgences
}

\section{Rêver, peut-être}

\section{Nancy Philibert}

Numéro 13, mars 1986

\section{Éclats d'atelier}

URI : https://id.erudit.org/iderudit/025222ar

DOI : https://doi.org/10.7202/025222ar

Aller au sommaire du numéro

\section{Éditeur(s)}

Urgences

\section{ISSN}

0226-9554 (imprimé)

1927-3924 (numérique)

Découvrir la revue

\section{Citer ce document}

Philibert, N. (1986). Rêver, peut-être. Urgences, (13), 51-52.

https://doi.org/10.7202/025222ar

Ce document est protégé par la loi sur le droit d'auteur. L'utilisation des services d'Érudit (y compris la reproduction) est assujettie à sa politique d'utilisation que vous pouvez consulter en ligne.

https://apropos.erudit.org/fr/usagers/politique-dutilisation/ 


\section{RÊVER, PEUT-ÊTRE Nancy Philibert}

L'homme roulait depuis des heures dans le brouillard et son esprit disputait entre deux envies: celle de rentrer chez lui le plus rapidement possible et celle de dormir... dormir, dormir juste quelques minutes le temps de récupérer. Sa main s'avança instinctivement vers le volume de la radio.

Le speaker relatait un fait historique tenant de la croyance populaire. Celui-ci faisait état d'un phare qui hantait la région depuis plus de deux siècles et qui amenait les navires à se jeter aveuglément sur une barrière de roches naturelles qui longeait la côte.

Soudain apparut, comme dans un rêve, le profil d'un orignal. Le réflexe endormi, I'homme alla percuter une énorme rembarde de béton...

Rien de cassé apparemment sinon la perte évidente du véhicule qui gisait là sous l'amas de béton qui était encore, quelques minutes auparavant, un mur.

Après s'être attardé sur les débris de son auto, son regard fureta sur le décor environnant. Derrière ce qui avait été l'emplacement du mur avant l'accident, il y avait un sentier qui menait à un pont. Lorsqu'il s'y engagea, la dernière chose qu'il aperçut, avant de disparaître derrière l'écran que formait le brouillard, fut la silhouette d'une énorme masse.

En effet, à peine avait-il fait quelques pas qu'il se sentit projeté vers l'autre extrémité. Encore ébloui par la soudaine clarté, il cligna des yeux pour s'apercevoir qu'il était seul sur un îlot en présence des ruines plus que centenaires, lui sembla-t-il, d'un vieux phare. Le pont avait disparu, de même que le brouillard, pour ne laisser place qu'à un éclatant soleil qui se reflétait sur une mer qui se perdait avec I'horizơn. Croyant à une hallucination, il fit quelques pas vers l'endroit où se situait le pont pour n'y trouver rien d'autre que des vagues venant s'échouer sur un escarpement rocheux. C'est en jetant un second 
regard sur la masse délabrée du phare qu'il sentit que quelque chose était sur le point de se produire. Á peine avait-il exprimé cette pensée que soudain ses yeux s'exorbitèrent à la vue du spectacle qui s'offrait à lui. Les rochers qui, tout à I'heure, jonchaient le sol à proximité du phare se mirent à s'élancer vers les ruines de celui-ci, s'imbriquant un à un jusqu'à complète reconstitution. On aurait dit un film passé en marche arrière. Tout ceci n'avait duré, au plus, que quelques minutes. L'homme se dirigeait vers ce qu'il croyait n'avoir été qu'un mirage pour finalement s'apercevoir qu'il en était tout autrement. Lorsqu'il y pénétra, un feu brûlait dans l'âtre. Pas de poussière ni de toiles d'araignée, tout semblait n'avoir été laissé que quelques minutes... et pourtant! Mu par une irrésistible envie, il se mit à gravir le très vieil escalier circulaire qui longeait le mur. Tout au long des sept étages, il gravit ces marches, rongées par le temps, pour finalement aboutir sur ce qui semblait être une passerelle.

L'appel soudainement lancinant d'une corne de brume ramena avec elle les décors brumeux qui officiaient à son arrivée sur le pont. Regardant à nouveau vers la côte, il put apercevoir, un peu en retrait, l'apparition graduelle d'un navire. Celui-ci, un très vieux modèle, avait tous les aspects des anciens galions et il semblait se diriger inexorablement vers la côte comme s'il ne pouvait l'apercevoir. Juste au moment où l'homme pressentait qu'il allait y avoir impact, la corne de brume fit retentir un autre appel. vide...

Ne perdit-il pas l'équilibre à ce point qu'il se vit basculer dans le

Lorsqu'il reprit conscience, il put voir devant lui le mur de béton qu'il avait percuté. Celui-ci était encore tout d'un bloc, contrairement à ce qu'il avait cru. Deux policiers le regardaient à travers les débris de son pare-brise, lui demandant s'il se sentait bien. C'était le bruit de la sirène, associé à la corne de brume, qui l'avait fait surgir de la torpeur dans laquelle il était plongé depuis l'accident.

La dernière chose qu'il vit, en s'en allant de ces lieux, fut l'image d'un sentier qui se dessinait derrière le mur et qui menait à un pont. 